\title{
FIRE IN THE HISTORY OF METTLER'S WOODS
}

\author{
Murray F. Buell, Helen F. Buell, and John A. Small \\ Botany Department, Rutgers, The State University of New Jersey \\ 75 Hamilton Street, New Brunswick, New Jersey, USA
}

Mettler's woods is an oak stand on the Piedmont of central New Jersey on the eastern edge of the town of East Millstone in Somerset County. The woods has been presumed to be, at least in part, a fragment of the forests that covered this section of the state before it was cleared by the white man. This presumption had its origin in a tradition in the succession of families that has owned the woods, that it has never been cut and cleared, and the presumption has been further supported by the soil profile, which is in amazing contrast with that of the surrounding fields.

Recently rather convincing evidence turned up following a severe windstorm in November 1950. One casualty of the storm was a fine, forest-grown white oak [Quercus alba L.] with an average basal diameter of 40 inches [101.6 cm]. It was not the largest oak in the woods at the time of the storm: a still larger one whose basal diameter is 51 inches [129.5 $\mathrm{cm}]$ is still standing. Although one cannot assume identical growth rates, it is probable that the latter tree is considerable older.

A slice of the base of the trunk of the fallen tree was brought into the laboratory in the fall of 1953 and careful notes were made along six different radii. Although rot has obscured the record in the outer part of the sapwood, a study of the growth rings shows that it started to grow about the year 1627. White settlement in this area was in 1701. Hence, this tree was about 74 years of age and 11 inches [27.9 cm] at the time settlement began.

During the first 84 years of life of the tree, or until 1711 there was a series of events that caused damage to the tree at its base, principally on the south and southwest sides of the tree. These damaged places were all rapidly healed over by vigorous growth. The presence of bits of charcoal in two of them indicates that they were caused by fire. Presumably the other scars were also caused by fire, since they are quite similar. (Figure 1.)

If the dating of the start of the tree is correct as 1627, the fires occurred at the following dates:

1641 at 14 years of age and 2 inches [5.1 $\mathrm{cm}$ ] in diameter

1652 at 25 years of age and 3 inches [7.6 $\mathrm{cm}$ ] in diameter

1662 at 35 years of age and 4 inches [10.2 $\mathrm{cm}]$ in diameter

1676 at 49 years of age and 6 inches $[15.2$ $\mathrm{cm}]$ in diameter

1701 at 74 years of age and 10.5 inches $[26.7 \mathrm{~cm}]$ in diameter

1711 at 84 years of age and 11 inches [27.9 $\mathrm{cm}$ ] in diameter

After the fire of 1711 there is no further evidence of fire scars in any radius.

The first four of these fires are undoubtedly a reflection of the use of fires by Indians. The setting of fires by Indians in the forests of northeastern United States was pretty well substantiated in the historical records, which are admirably summarized by Day (1953). His earliest record (Juet 1610) for New Jersey is "a great Fire" which Hudson's crew saw somewhere south of Sandy Hook. He then includes a series of reports of the Indians' intentional and accidental burning of the New Jersey forests, and states (citing Loskiel 1794) that "The Lenape Indians continued to burn 


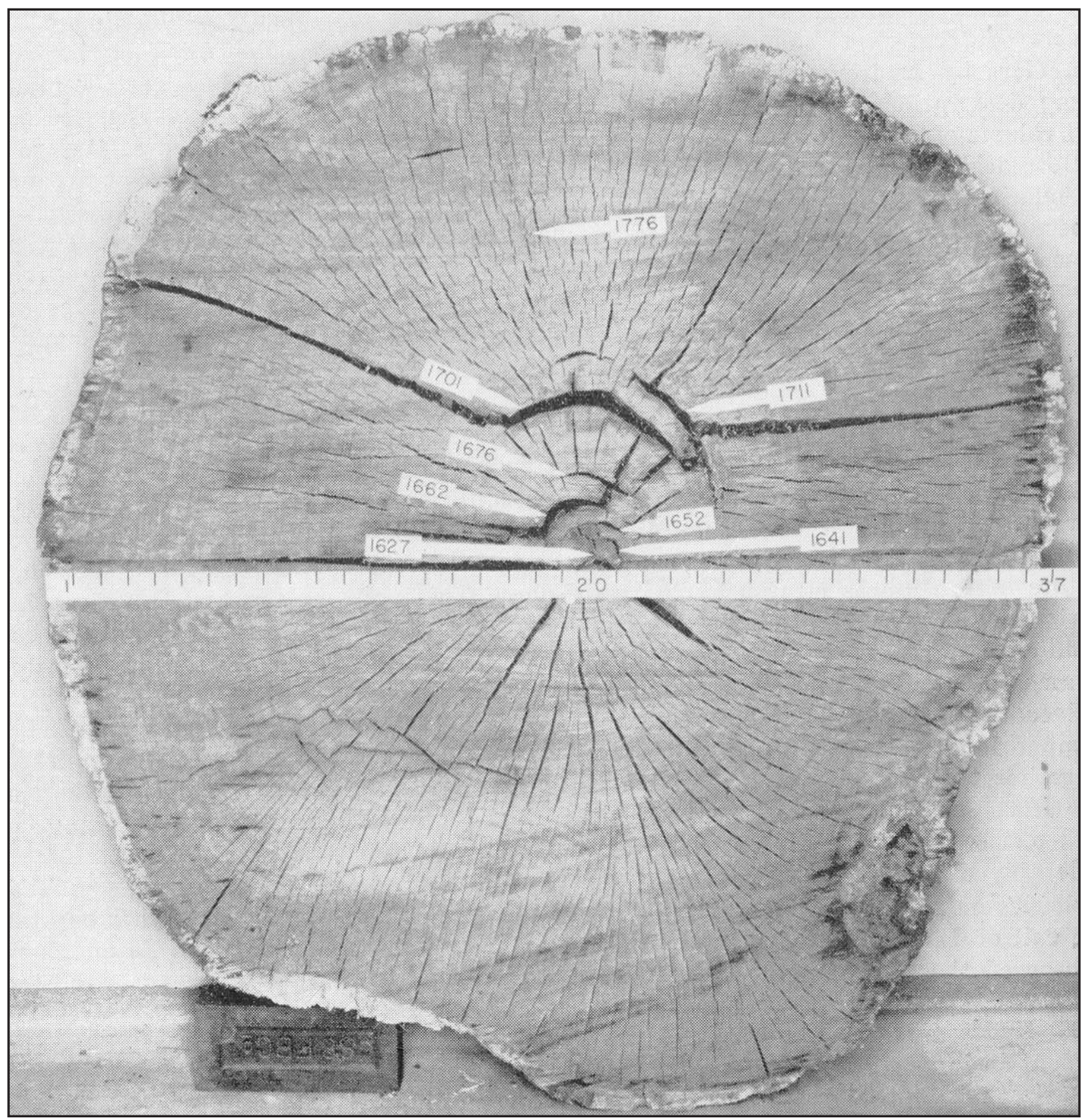

Figure 1. Section from base of white oak tree from Mettler's Woods. Arrow bearing the date 1627 points to the center of the tree. Those with $1641,1652,1662,1676,1701$, and 1711 point to fire scars. The arrow with 1776 simply indicates the size of tree at that historical date. The horizontal white strip is marked off in inches. (Photo by F.J. Higgins.)

the woods deliberately in the spring and fall and accidentally at other times after they had left New Jersey." Day also cites writings by Denton in 1670 who, commenting on the country between the Raritan and the Delaware Rivers, mentioned the forests of "stately Oaks" with "broad-branched tops," and noted the customary spring burning.

The record left by the large tree in Mettler's woods essentially corroborates the reports of burning by Indians. However, the fact that the fire scars occur at intervals of ten 
years or more suggests that the area was not burned annually. If annual fires had been the rule, the amount of litter accumulating at the tree base as fuel probably would not have been sufficient to have resulted in a fire of great enough intensity to have damaged the tree. Although litter is rather rapidly incorporated into the soil at Mettler's woods, there is an accumulation of fuel on the forest floor for a period of about three years. Under present conditions, at least, a longer period without fires would not appreciably add to the fuel supply. Drier periods, however, preceded several of the fires, at least as suggested by series of narrow rings. This is true for the 1662, 1676, 1701 and 1711 fires. During a series of such dry years, litter accumulation might be greater, and also fire coming during an especially dry season of such a succession of years would be especially damaging.

The present dominants of Mettler's woods are oaks and hickories, primarily white, black, and red oaks (Quercus alba, Q. velutina, and Q. rubra) [Quercus alba L., Q. velutina Lam., and $Q$. rubra L.] and red [pignut] hickory (Carya ovalis) [Carya ovalis (Mill.) Sweet]. It appears obvious that these trees had their origin during a period of frequent fires. While it is not possible to be certain what sort of forest stood on this site before our record starts, it is probable that the Indians' practice of burning the forest had been a long-standing one, and hence species with at least some fire resistance must have long been dominant. The oak element of forests occurring in more mesic forest areas has been shown to be favored by fire history (Eggler 1938).

The future composition of this forest has been the subject of some debate, although Bard (1952) is the only one who has so far published the arguments for and against its perpetuation as an oak-hickory forest. If the woods is preserved, it will be possible to follow its natural development.

This article was reprinted with permission from Buell, M.F., H.F. Buell, and J.A. Small. 1954. Fire in the history of Mettler's woods. Bulletin of the Torrey Botanical Club 81: 253-255. Copyright 1954 by the Torrey Botanical Club.

\section{LITERATURE CITED}

Bard, G.E. 1952. Secondary succession on the Piedmont of New Jersey. Ecological Monographs 22: 195-215. doi: 10.2307/1943565

Day, G.M. 1953. The Indian as an ecological factor in the northeastern forest. Ecology 34: 329346. doi: $10.2307 / 1930900$

Denton, D. 1670. A brief description of New York. Edited by W. Gowans, 1845. William Gowans, New York, New York, USA.

Eggler, W.A. 1938. The maple-basswood forest type in Washburn County, Wisconsin. Ecology 19: 243-263. doi: 10.2307/1929640

Juet, R. 1610. The third voyage of Master Henry Hudson. Original Narratives of Early American History 8(1909): 11-28.

Loskiel, G.H. 1794. History of the mission of the United Brethren among Indians in North America. Translated by C.I. La Trobe. No publisher [Brethren Society for the Furtherance of the Gospel], London, England, United Kingdom. 